\title{
THE CALORIGENIC ACTION OF THYROXIN POLYPEPTIDE
}

\author{
By W. T. SALTER, J. LERMAN AND J. H. MEANS \\ (From the Thyroid Clinic of the Massachusetts General Hospital, Boston)
}

(Received for publication October 19, 1932)

In 1930 Harington and Salter (1), by subjecting thyroid to proteolytic digestion, obtained a product which proved to be thyroxin in peptide combination. This substance having an iodine content of 49 per cent by weight has a far wider range of solubility than pure crystalline thyroxin. It was concluded by these writers that thyroxin actually exists "in the thyroid gland in peptide combination-as a constituent aminoacid, in fact, of the characteristic thyroid protein, iodothyreoglobulin." It was further adduced that this substance alone is responsible for the physiologic action of whole thyroid gland and that the differences in action of dried thyroid and crystalline thyroxin depend solely on differences in the physical properties of thyroxin and thyroxin polypeptide, that is to say, their solubilities, optical activities, and availabilities to the body by different routes of entry. To determine the correctness of such an hypothesis it would be necessary to compare the calorigenic action of thyroxin, thyroxin polypeptide and whole thyroid gland. A direct comparison between thyroxin and thyroid is impossible because the former exerts its action quantitatively only when given parenterally and the latter can be given safely only via the gastro-intestinal tract. It was hoped that since thyroxin polypeptide is more soluble than thyroxin, it might be better absorbed by mouth and that, therefore, thyroxin and thyroid if not comparable directly with one another could each be compared with polypeptide.

The present report deals with the calorigenic action of thyroxin polypeptide by the parenteral and enteral routes, and also a comparison with that of pure thyroxin parenterally. The comparison of polypeptide and thyroid by mouth will be made the subject of a later report.

The assay was carried out in patients suffering from complete, untreated, spontaneous myxedema. No other type of patient was used. In each case a row of basal metabolism determinations was made on successive days prior to the administration of any thyroid preparation until what was regarded as a true basal level had been obtained. After that, determinations were made as nearly daily as possible until such time as was thought necessary in order that the drug might have its maximum effect. No patient was used for more than one assay. 
The first series of observations was upon the effect of daily oral rations of $1 \mathrm{mgm}$. of thyroxin polypeptide. ${ }^{1}$ Five myxedema patients were studied under this regime. The individual calorigenic responses are shown graphically in Figure 1, together with the composite of the five.

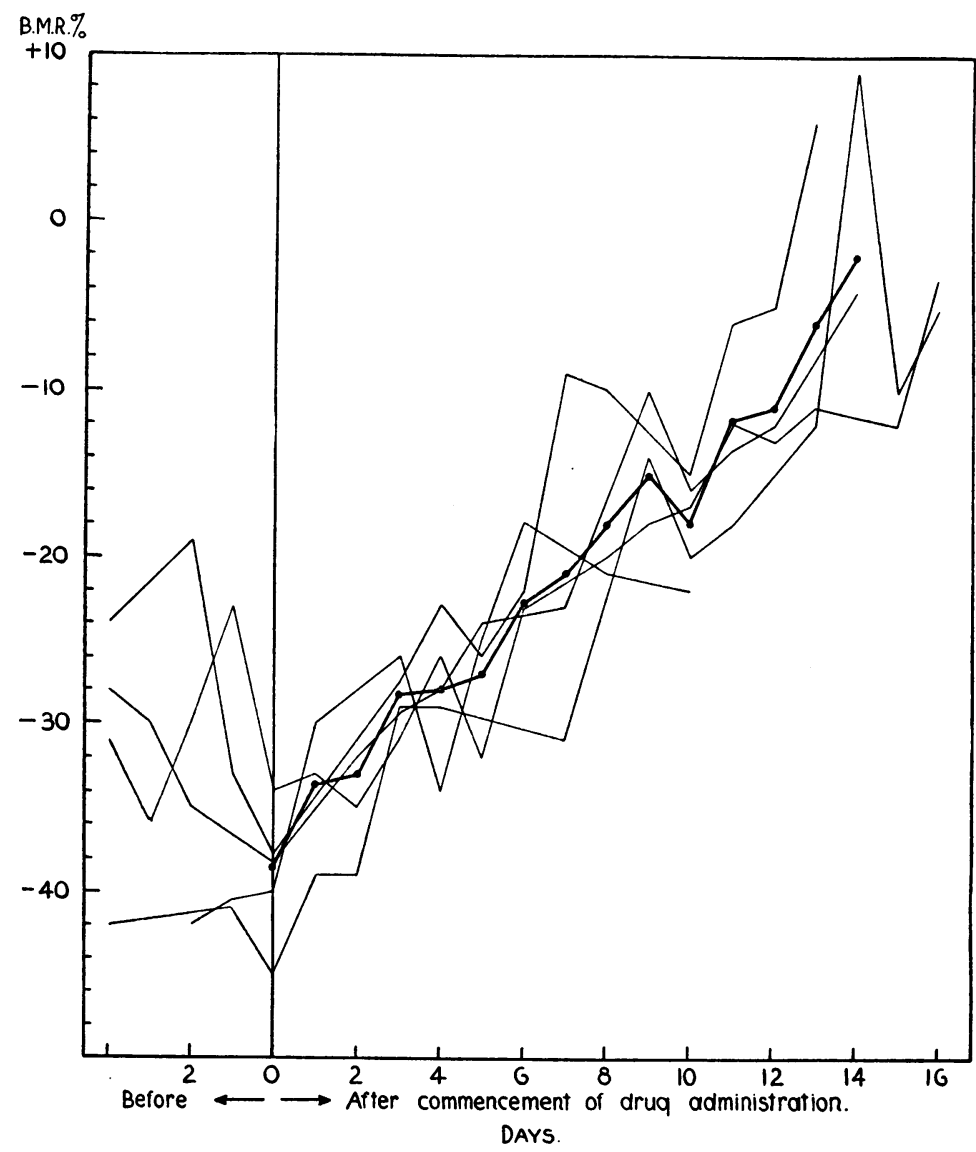

Fig. 1. The Calorigenic Response to the Daily Oral Administration of 1.0 mgm. OF Thyroxin Polypeptide (Containing 0.5 mgm. of Iodine) in Five Cases of Myxedema.

The light lines represent the individual responses, the heavy, the composite.

1 The preparation of polypeptide used was prepared by one of us (W.T.S.) in the laboratory of Dr. C. R. Harington to whom our thanks are due for this opportunity. It should be noted that from this material, free thyroxin had been removed. Its iodine content was 49 per cent by weight and its total nitrogen 3.3 per cent. These figures indicate that the material is a mixture of peptides. On the average there are between two and three amino groups in the peptide chain attached to each nucleus of four iodine atoms. One of the amino groups belongs to thyroxin proper. The last amino group is free. 
Although the individual curves show the irregularities to be found in any basal metabolic curve, their trends are quite similar and the group as a whole indicates a pronounced response of a very definite order of magnitude. The slope of the curve is in the neighborhood of 2.5 points per day.

We next conducted a series of observations on the same ration of polypeptide, this time given intravenously. This was done in four myxedema patients. The results are shown in Figure 2. These curves, although

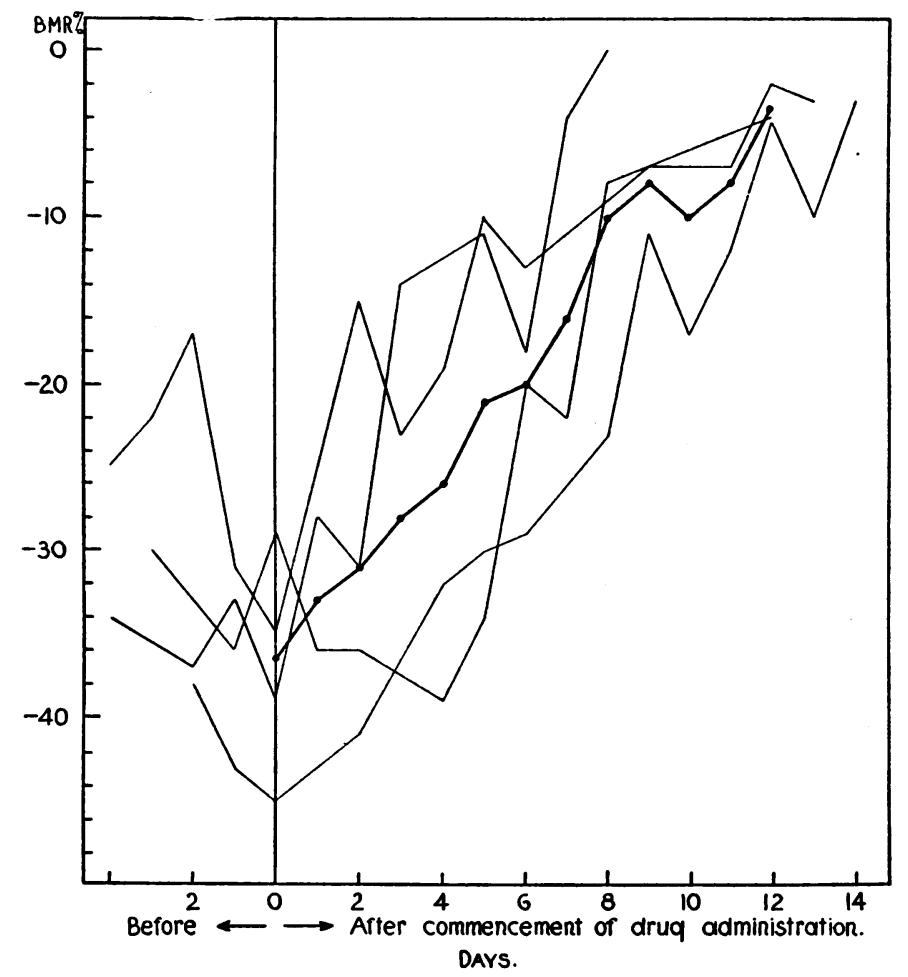

Fig. 2. The Calorigenic Response to the Daily Intravenous Administration of 1.0 mgm. OF Thyroxin Polypeptide (Containing 0.5 MGM. OF Iodine) In Four Cases of MyXedema. posite.

The light lines represent the individual responses, the heavy, the com-

somewhat more irregular than the previous group, also furnish evidence of a striking calorigenic response. The slope of the composite appears to be very similar to that of the oral group being in the neighborhood of 2.7 points per day.

Our next procedure was to compare the effect of polypeptide when given by the oral with that by the intravenous route when a single dose of $13 \mathrm{mgm}$. was employed instead of a daily ration of $1 \mathrm{mgm}$. One curve 
was obtained for each route. They are shown in Figure 3. Of these two responses that to intravenous administration is slightly greater but not to a degree that one can say is significant. The intravenous curve reaches its maximum on the sixth day at a rate of 5.2 points per day.

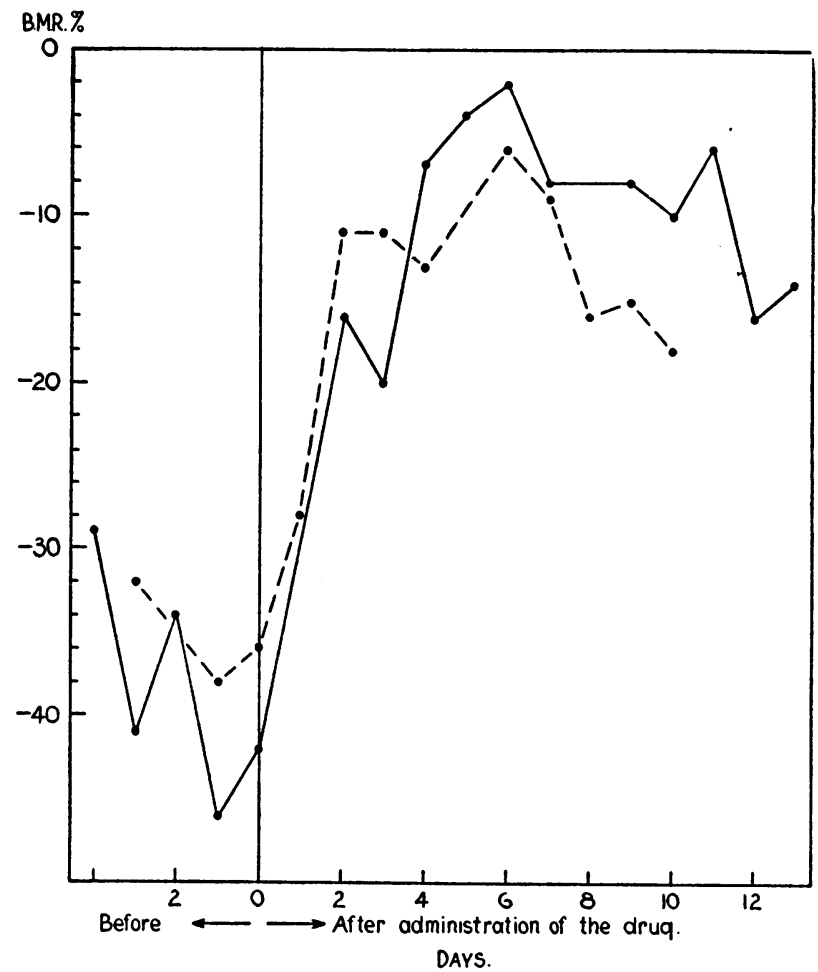

Fig. 3. The Calorigenic Response to a Single Intravenous Injection of 13 mgm. of Thyroxin Polypeptide (Containing 6.5 mgm. of Iodine) in a Case of Myxedema, Shown by the Solid Line, and that to the Same Agent and Dose by the Oral Route in Another Case of MyXedema SHOWN BY THE INTERRUPTEd LiNe.

We have also compared the intravenous $13 \mathrm{mgm}$. single dose polypeptide curve with two curves obtained in this clinic by Thompson (2) showing the response to a single intravenous injection of $10 \mathrm{mgm}$. of crystalline thyroxin which has the same iodine content as $13 \mathrm{mgm}$. of polypeptide. This comparison is made in Figure 4. It can be asserted with confidence that no significant differences exist among these three. In fact the polypeptide curve for the most part lies actually between the two thyroxin curves with which it is compared.

Finally, we may present assays in two other cases in each of which $10 \mathrm{mgm}$. of thyroxin polypeptide was given in a single dose by mouth. Ten mgm. of polypeptide contains $4.9 \mathrm{mgm}$. of iodine. Therefore it is 
appropriate to compare these with an assay of $7.5 \mathrm{mgm}$. of thyroxin obtained by Thompson, ${ }^{2}$ this having the same iodine content. These three curves are shown in Figure 5. They are quite similar and furnish added evidence of the identity of response to pure thyroxin and its polypeptide on the one hand, and of the excellent absorption of the latter by mouth on the other.

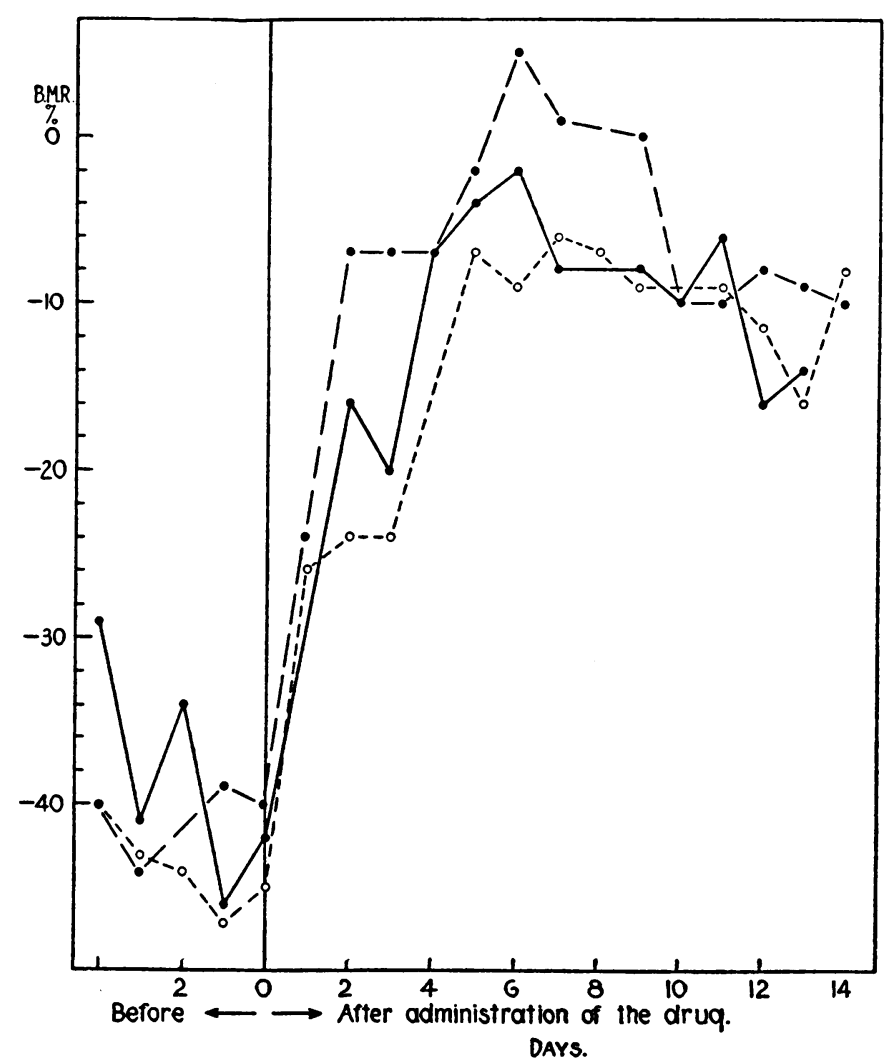

Fig. 4. The Calorigenic Response to a Single Intravenous Injection of Thyroxin Polypeptide (Containing 6.5 mgm. of Iodine) Shown by the Solid Line (the Same Assay as Shown in Figure 3), Compared with the Response in Two Patients with Myxedema Each of Whom Received a Single Intravenous Injection of 10 mgm. of Crystalline Thyroxin (also Containing 6.5 mgm. OF IOdine) Shown by the INTERRUPted Lines.

2 This observation was made by Dr. W. O. Thompson at the Presbyterian Hospital, Chicago. We are indebted to him for permission to use it here for comparison with our data. The case was one of post-thyroidectomy hypothyroidism not spontaneous myxedema. Prior to the administration of thyroxin the patient had been given diiodotyrosine intravenously for two weeks, in doses varying between 240 and $1000 \mathrm{mgm}$., daily. It had had no noteworthy calorigenic effect. 
This group of curves as a whole indicates a somewhat smaller response than the group shown in Figure 4 which suggests that our method of assay is sufficiently delicate to distinguish between $6.5 \mathrm{mgm}$. and $4.9 \mathrm{mgm}$. of iodine whether given in the form of pure thyroxin or in that of polypeptide.

It should be noted that the symptomatic response to polypeptide in every assay made was in all respects identical to what would be expected

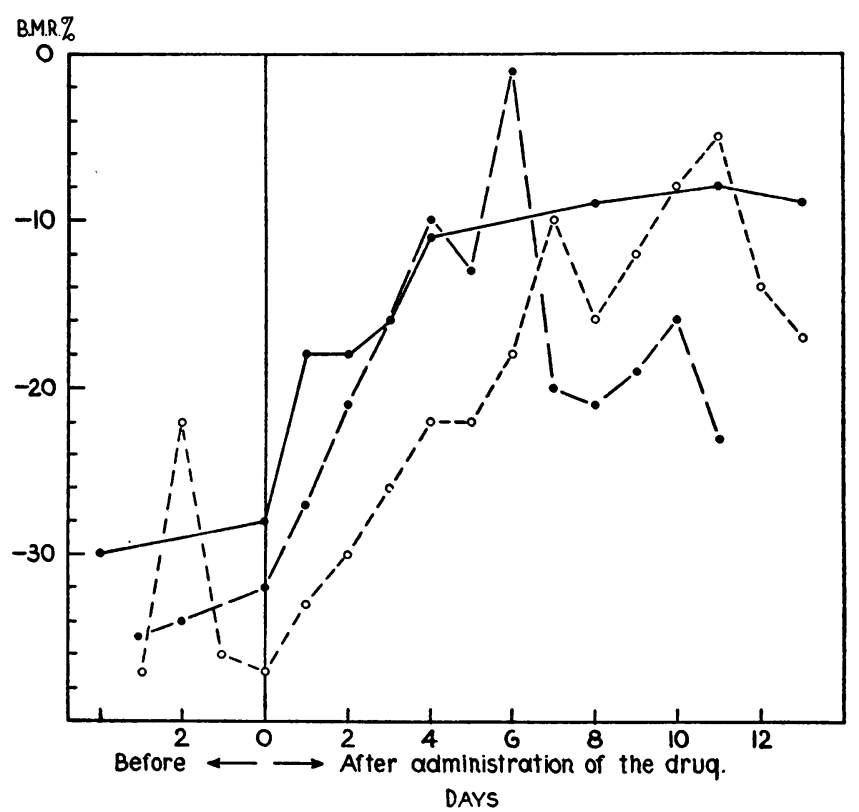

Fig. 5. The Calorigenic Response to a Single Intravenous Dose of 7.5 mgm. of Crystalline Thyroxin (Containing 4.9 mgm. of Iodine) Obtained by Thompson in a Case of Postoperative Hypothyroidism Compared with Those Obtained by us in Two Cases of Myxedema, after a Single Oral Dose of 10 mgm. of Thyroxin Polypeptide (also Containing 4.9 MGM. OF (ODINE).

after either whole thyroid or thyroxin. Furthermore studies by the $\mathrm{x}$-ray and electrocardiograph showed changes resulting from polypeptide entirely similar to those seen in myxedema under thyroid.

\section{COMMENT}

The ideal assay of the calorigenic action of a hormone would be the administration of a single effective dose to a hormoneless subject and the observance of the complete curve of response both in its ascending and its descending limbs. The area subtended by such a curve represents the totality of extra calories produced by the hormone administered. Certain practical obstacles to the collection of such data, however, present 
themselves. With regard to the descending limb there is the difficulty that the effect of a single dose of thyroxin may be detectable in the myxedematous human for as long as $\mathbf{9 0}$ days, and the full descending limb cannot be observed without allowing the subject to become for a second time completely myxedematous. This of course is undesirable on humanitarian grounds and also because of the long periods of hospitalization required, it is very expensive. Inasmuch as the calorigenic response of myxedema patients to whole thyroid or thyroxin is quantitatively related to the dosage given, we contented ourselves with the observance of the ascending limb only, believing that its slope would be for all ordinary intents and purposes a satisfactory basis of comparison. The descending limb has to do more with rate of destruction of the hormone than with its immediate calorigenic potency.

With regard to the single large dose method, when the enteral route is being studied, there is the possibility of failure of absorption. It was for that reason that we began our study with divided doses by mouth and perforce these were compared with equal divided doses intravenously. Daily rations of small doses further have the advantage over single large doses that the unknown factors of destruction and excretion of the hormone are minimized. Also in dealing with a new substance we wished to avoid any possible toxic effect not possessed by other thyroid preparations by beginning with small doses.

The interpretation of the data presented in Figures 1 and 2 offers some difficulties. It certainly can be said that the calorigenic effect of divided doses by mouth approaches very closely to that by the intravenous route. It would not be sound on the basis of the present data to claim that they are identical. When we come to the comparison of single doses of $13 \mathrm{mgm}$. the two observations show slight, but very likely insignificant, differences.

As to the identity of response of pure thyroxin and its polypeptide intravenously, when given in doses of equal iodine content, we believe there can be no doubt. This conclusion is at variance with that reached by Harington and Randall (3) to the effect "that any remaining discrepancy which appears to exist between the physiological activity of thyroid gland and that of an equivalent amount of thyroxine may be accounted for by an enhancement of the activity of the latter compound when it is in peptide combination." These authors recognized the fact that whole thyroid gland shows more calorigenic activity than the thyroxin (racemic) contained in it would account for but sought to explain this by assuming that optical activity of thyroxin and possibly also the fact that it is in peptide combination enhanced its physiologic potency. The present work reveals no such enhancement.

The observations here reported we believe are also important because in thyroxin polypeptide we have a link which makes possible the compari- 
son of pure thyroxin and whole gland preparations, which cannot be compared directly one with another. This opens the way to further study of thyroid physiology. At the present time we have in progress a study of the action of whole gland preparations having different ratios between their so-called active and inactive moieties, using as a means of comparison the curve of the divided oral dose of polypeptide. This will be the subject of a further report in the near future. We may say at the present moment the results seem to favor the view that the calorigenic action of whole gland depends upon its total rather than upon its active iodine content. ${ }^{3}$

\section{CONCLUSIONS}

1. A preparation of thyroxin polypeptide containing 49 per cent of iodine has been found through assay in persons suffering from myxedema to have a calorigenic action when given by mouth closely approaching that which it exerts when given intravenously. This holds true whether the comparison is made of single large doses or of repeated small daily rations. These findings indicate a high degree of absorption of thyroxin polypeptide from the gastro-intestinal tract.

2. The calorigenic action of thyroxin polypeptide given intravenously is identical with that of pure thyroxin when doses of the two drugs are employed in which the total iodine content is the same.

\section{BIBLIOGRAPHY}

1. Harington, C. R., and Salter, W. T., Biochem. J., 1930, xxiv, 456. The Isolation of $l$-thyroxine from the Thyroid Gland by the Action of Proteolytic Enzymes.

2. Thompson, W. O., Thompson, P. K., Brailey, A. G., and Cohen, A. C., J. Clin. Invest., 1929, vii, 437. The Calorigenetic Action of Thyroxin at Different Levels of Basal Metabolism in Myxedema.

3. Harington, C. R., and Randall, S. S., Biochem. J., 1929, xxiii, 373. Observations on the Iodine-containing Compounds of the Thyroid Gland; Isolation of $\mathrm{dl}-3$ : 5-di-iodotyrosine.

3 By "active" is meant the fraction which is not soluble in weak acid after digestion with alkali. See Harington and Randall (3). 